\title{
Human preference for nonconflict vs conflict situations
}

\author{
ALAN C. REPP* and WILLIAM D. WOLKING \\ University of Florida, Gainesville, Fla. 32603
}

Ss responded in two conditions, one of conflict and one of nonconflict. In the conflict condition, responding both added and subtracted points, while in the nonconflict condition, responding only added points. The net gain in points, however, was equal in both situations. After 10 sessions of responding in both conditions, Ss could control which was in effect by pressing a second manipulandum. Response rates were slightly higher in the nonconflict condition than in the conflict. The responses to change to the nonconflict condition, however, were much greater than those to change to the conflict condition.

Conflict refers to situations in which a response simultaneously has two different consequences. For example, in the classic experiment on approach-avoidance conflict (see Miller, 1959), running down an alley produced both food and an electric shock. The result was that rats eventually approached the goalbox, but the speed of approach was less than when there was no shock.

Although there has been research using the conflict procedure, there is little information about preference between conflict and nonconflict situations. The present study provided such information in two ways. During one stimulus condition, pressing a manipuiandum both added and subtracted points on a counter. During a second stimulus, the response only added points; however, the net gain was the same as with the first stimulus. These conditions (multiple schedule) indicated whether, when a S did not have the opportunity to choose between the stimuli. the rate of responding depended on the net point gain or on conflict vs no conflict. In a second set of conditions (concurrent schedule), the Ss controlled which of the two stimuli was present. Such a procedure has been found to be a sensitive measure of preference (e.g., Catania, 1966; Herrnstein, 1970) and seemed likely to reveal differences not detected by the multiple schedule. However, the technology of concurrent schedules has shown that the specific behavior required to change from one schedule to another is itself an important determinant of preference (Findley, 1958). Therefore, the present experiment also manipulated the requirements for choosing between the two conditions of the concurrent schedule.

$$
\text { SUBJECTS }
$$

Two boys and one girl, ages 7,8 ,

* Now at Georgia Retardation center. Atlanta. Ga. 30341 and 11 , served as Ss. All attended local public schools, and none had previously participated in an experiment of this type.

\section{APPARATUS}

Each $S$ was seated alone in an experimental chamber $3 \times 5 \mathrm{ft}(.91 \times$ $1.52 \mathrm{~m})$ and faced a $12 \times 12$ in. $(.31 \times$ $.31 \mathrm{~m}$ ) display panel mounted in a cabinet on the front wall and centered $3 \mathrm{ft}(.91 \mathrm{~m})$ above the ground. Two microswitch buttons, requiring a force of approximately $20 \mathrm{~g}$ through a distance of $1 \mathrm{~cm}$, were mounted on the panel. Above the manipulanda, in three rows, were a row of two red $7 \cdot W$ lamps, a row of four (green, yellow, white, and clear) $7 \cdot \mathrm{W}$ lamps, and an add-subtract couritei. A tone joundad simultaneously with the operation of the counter.

The two red lamps were always lighted and provided the only general illumination. The other four lights were correlated with stimulus conditions. White noise, delivered through a loudspeaker above the stimulus panel. helped to mask extraneous sounds. A clicking noise, associated with one stimulus condition, was delivered through the same loudspeaker.

\section{PROCEDLRE}

The experiment was conducted in two phases. In Phase 1, a two-component multiple schedule, in which components alternated after each addition of a point, was in effect. In the presence of a white light, points were added winen a fixed-ratio (FR) requirement was met. In the presence of a yellow light, points were added when a FR requirement was met and were subtracted when a variable-ratio (VR) requirement was fulfilled. Arbitrarily, the FR value of the first component was selected as 2.5 times that of the second. In order to ensure that at the end of a session each component resulted in the same number of total points, the VR schedule was selected as 1.67 times that of the Fit viue it tis sccond component $(1 / 2.5=1 / 1.0-1 / 1.67)$.

Each $S$ responded at a different rate, and therefore different amounts of money could have been earned if the schedules had been the same for all. In accord with a policy of keeping the daily sums earned by each $S$ as similar as possible, the FR schedules and the value of each point accrued was varied between Ss. The schedules for $\mathrm{Ss} 1,2$, and 3 were mult (FR $250+$ ) (FR $100+$ VR 167-), mult (FR $220+)(F R 88+V R$ 1.17-), and mult (FR 240+) (FR 96+ VR 160-), respectively, while each point was valued at $2 c, 3 c$, and $3 c$, respectively (each component appears within one set of parentheses, and the plus and minus signs indicate whether the schedule involved point gain or point loss ).

Each $30-\mathrm{min}$ session began with the add-subtract counter set at zero. The instructions for Session 1 were: "You can change the number on this counter by pressing the button on your right, and a tone will sound each time there is a point change. The overhead light will be off, but the two red lights will be on so that you can see the number on the counter. Sometimes the yellow and sometimes the white light will be on. When either is on, you can push the button on your right; when neither is on, the session is over. At this time, you will have earned ___ pennies for every point on the counter." When a session terminatod, tho child signed a ledger in which the points earned were totaled. When the experiment ended, the children were paid according to the number of points earned.

The multiple schedules were in effect for a minimum of 10 sessions and until the response rate in each component in each of the last five sessions did not differ from the mean of the rates of that component by more than $10^{\circ} \mathrm{c}$.

Phase 2 began after the multiple-schedule condition was completed. Responses to the right button still added or subtracted points, and the schedule prevailing on that button was indicated by which lamps (white or yellow) were lit. Now, howevar, the $S$ could change the stimulus and schedule by pressing the left button (the changeover button). After the first changeover response, several events occurred: responses on the right button were no longer effective, the light associated with the component in effect was terminated, and a green light was illuminated. After the number of responses that fulfilled the changeover requirement occurred, the right manipulandum was engaged, the light associated with the new component was illuminated, the green light was terminated, and a $3 \cdot \mathrm{sec}$ 
MULTIPLE

CONCURRENT

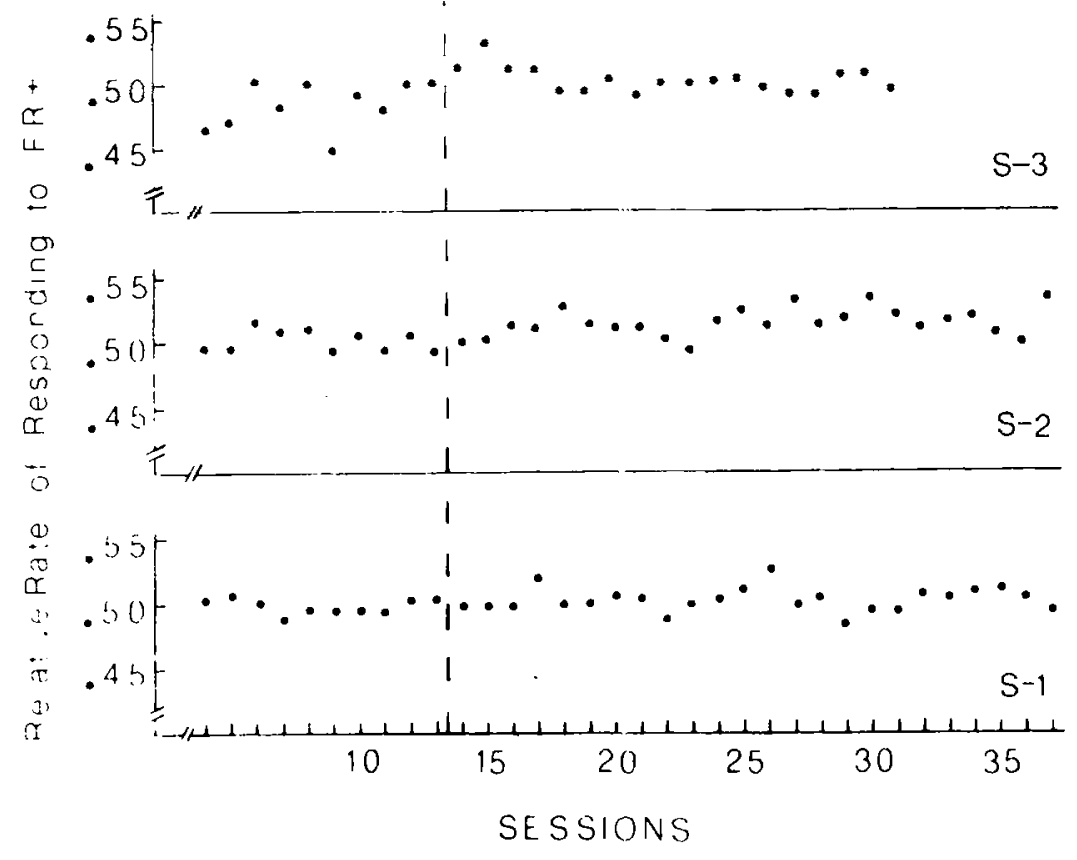

Fig. 1. The relative rate of responding in the FR+ component for each session.

period, during which points could neither be added nor subtracted, began. A changeover from a component did not result in the ratio's being reset for that component.

The instructions for the concurrent schedule were: "You can change the yellow light to white, or the white light to yellow, by pressing the button on your left. If the green light comes on when you press the left button, press carefully until it goes off; the lights will then change."

In the first two sessions, two responses were required to change from one component to the other. The clear lamp was lit and the clicker sounded throughout the entire session as stimuli correlated with this changeover requirement. Starting with the third session, whenever at least $75 \%$ of the changeovers were to one stimulus, the changeover requirement for the next session was increased by two. This procedure was continued until no changeovers occurred for three consecutive sessions. In the final session of the experiment, the changeover requirement of two was reinstituted with the clicker and clear light on to determine if the earlier behavior was recovered.

\section{RESULTS}

The data are presented in two forms, the rate of responding and changeovers. All Ss began final schedule values on Session 4 and satisfied the stability criterion for the multiple schedule on Session 13. The concurrent schedule then began.

Figure 1 shows the relative frequency of responding to the FR+ component. Each point on the graph represents a value derived by dividing the rate of responding in the FR+ component by the sum of the response rates in the FR+ and FR+ VRcomponents. While the multiple schedule was in effect, Ss 1 and 2 responded at the same relative rate in each component. Rates for S 3, however, were slightly, but consistently, lower in the FR+ component. When the concurrent schedule was in effect, the relative rates were slightly higher in FR+ for each $\mathrm{S}$ than they were in the multiple schedule.

The absolute rate of responding was slightly higher in Phase 2 than in Phase 1 for each $S$. However, this study focused on the difference in rates between components rather than on the difference in rates between phases for a single component. The relative rate of responding does focus on rate differences between components and is not affected by the rate differences between phases.

The second form of data describes the responses that changed the component in effect. Figure 2 shows the relative changeovers to FR+. All Ss preferred the FR+ to the FR+ VRcomponent, although the extent and the pattern of changeover responses varied between $S s$. Changeovers by $S 2$ and $S 3$ were scattered throughout each session, while changeovers by $\mathrm{S} 1$ occurred near the end of each $1 / 2-h$ session, usually after 35 points had accumulated on the counter.

Changeover responding by $\mathrm{S} 3$ differed from that of the other Ss when a short (three-session), but consistent, preference for FR+ VRdeveloped. When the changeover requirement was 6,8 , and $10, \mathrm{~S} 3$ demonstrated this preference, but returned to choosing FR+ for the remaining sessions. The other Ss maintained an early preference for the FR+ component.

Changeover responding by Ss 1 and 3 ceased when the changeover requirement was increased to 20 and 24 responses, respectively. When the changeover requirement was reduced and the stimuli (clear light and clicker) correlated with this requirement were instituted again, the behavior recovered and the FR+ component was chosen. For S 2, changeovers continued even when the requirement was 36 responses. At this changeover value, the experiment was concluded.

The absolute number of changeover responses differed between Ss. The most changeover responses were made by $S 2: 4,330$ to $F R+$ and 172 to FR+ VR-. The total responses to change to the FR+ and FR+VR- schedules were 1,418 and 244 for $S 3$ and 376 and 52 for $\mathrm{S} 2$, respectively. For each $\mathrm{S}$ considered individually, the Wilcoxon matched-pairs signed-ranks test (Siegel, 1956) indicated statistical significance for changeovers to the FR+ component $(p<.01)$.

\section{DISCUSSION}

As Catania (1966) has indicated, the changeover-key procedure (one manipulandum for responding to schedules and one for changing schedules) separates the two components of concurrent schedules: the multiple schedule or discriminative responding and changeovers or choice. In the present study, the multiple schedule was not as sensitive as the concurrent schedule to the differences between the reinforcement schedules; response rates did not vary appreciably between components. Morse (1966), in reporting an unpublished experiment with Skinner, has discussed the occasional insensitivity of multiple schedules to low and moderate FR requirements. For values of FR up to 300 , there was little difference in response rates under two conditions of reinforcement magnitude. Only at FR 600 did the multiple schedule demonstrate larger differences between response rates.

Changeover data were more sensitive to schedule differences in the present experiment. Clearly, each S preferred the nonconflict to the conflict situation. This result is similar 


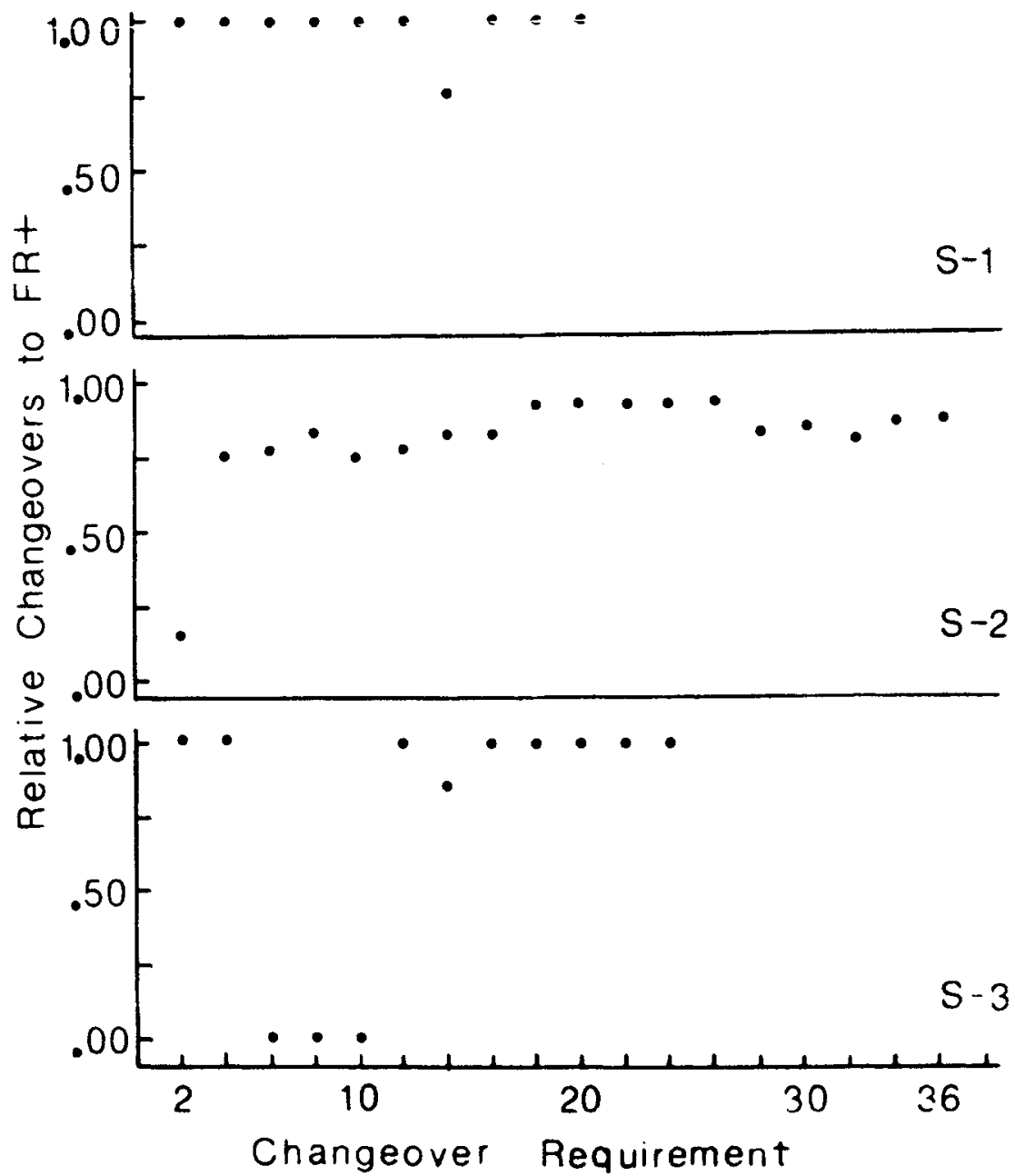

Fig. 2. The relative changeovers to the FR+ component on the final session at each changeover requirement.

to that found by Hearst \& Sidman (1961), who reported, for some Ss, preference for a neutral situation to one in which food was presented on a variable-interval schedule and shock was presented on a fixed-ratio schedule. Holz, Azrin, \& Ayllon (1963) also found that Ss preferred a imposed on one schedule, the frequency of reinforcement was less on that manipulandum than on the other. By alternating cigarettes on one manipulandum with cigarettes and noise on another, Herman \& Azrin (1964) equated the frequency of cigarettes in each situation. Ss in this study also responded much more often on the nonconflict manipulandum. The present study extended these by equating the gain in one situation, nonconflict, with the net gain (points added-points lost) in the other, or conflict, situation. The results were similar to those of the previous studies: Ss preferred to respond in the nonconflict situation.

REFERENCES

CATANIA, A. C. Concurrent operants. In W. K. Honig (Ed.), Operant behavior: A reas of research and application. New York: Appleton-Century-Crofts, 1966. Pp. 213-270.

FINDLEY, J. D. Preference and switching under concurrent scheduling. Journal of the Experimental Analysis of Behavior, $1958,1,123-144$.

HEARST, E., \& SIDMAN, M. Some behavioral effects of a concurrently positive and negative stimulus. Journal of the Experimental Analysis of Behavior. $1961,4,251-256$.

HERMAN, R, L., \& AZRIN, N. H Punishment by noise in an alternative response situation. Journal of the Experimental Analysis of Behavior, 1964 , 7. 185-190.

HER RNSTEIN $R$ J On the law of effect Journal of the Experimental Analysis of Behavior, 1970, $13,243-266$.

HOLZ, W. C., AZRIN, N. H., \& AYLLON, T. Elimination of behavior of mental patients by response-produced extinction. Journal of the Experimental Analysis of Behavior, 1963,6.407-412.

MILLER, N. E. Liberalization of basic S-R concepts: Extensions to conflict behavior, motivation, and social learning. In S. Koch (Ed.), Psychology: A study of science. New York: McGraw-Hill, 1959. Pp. 196-292.

nonconflict to a conflict situation When responding was followed by cigarettes on one manipulandum and by. both cigarettes and extinction (periods in which cigarettes were not available) on a second manipulandum, Ss responded much more on the first. Because extinction periods were
MORSE, W. H. Intermittent reinforcement. In W. K. Honig (Ed.), Operant behavior: Areas of research and application. New York: Appleton-Century-Crofts, 1966. Pp. 52-108.

SIEGEL, S. Nonparametric statistics. New York: McGraw-Hill, 1956. 